\title{
Diferencias morfológicas relevantes para la identificación específica de larvas de uncinarias y Strongyloides stercoralis
}

\author{
Relevant morphological differences for the specific identification of larvae of hookworms and Strongyloides \\ stercoralis
}

Heber Silva-Díaz ${ }^{1}$

RESUMEN

Objetivos: Describir las características morfológicas diferenciales más relevantes de los estadíos larvarios de uncinarias (Ancylostoma duodenale y Necator americanus), y S. stercoralis, para su identificación específica en laboratorio clínico convencional. Material y métodos: Estudio observacional durante julio del 2015 a agosto del 2016. Se realizaron cultivos en placa de agar de muestras fecales positivas por microscopía a larvas de nematodos o huevos de uncinaria. Las larvas desarrolladas en cultivo fueron descritas morfológicamente mediante claves, se identificaron las características morfológicas diferenciales más relevantes y se ilustraron mediante microfotografías. Resultados: Las características morfológicas más relevantes para la diferenciación específica fueron la longitud de la cavidad bucal y la prominencia del poro genital en el estadío rabditiforme; y la forma del cuerpo, el extremo terminal de la cola y el diámetro del extremo anterior del intestino en relación al esófago en el estadío filariforme. Conclusiones: Las uncinarias $A$. duodenale y $N$. americanus, y $S$. stercoralis pueden identificarse específicamente por microscopía óptica mediante el análisis morfológico de sus estadíos larvarios desarrollados en cultivo. Debido al requerimiento de equipos e insumos de uso común en laboratorio de microbiología, se recomienda esta metodología para uso en laboratorios clínicos convencionales.

PALABRAS CLAVE: Strongyloides stercoralis, Ancylostomatoidea, Necator americanus. (Fuente: DeCS BIREME).

\section{SUMMARY}

Objectives: To determine the most relevant morphologic differences of larval stages of hookworms (Ancylostoma duodenale y Necator americanus) and S. stercoralis for their specific identification in a conventional laboratory. Methods: An observational study was carried-out between July and August 2016. Positive fecal samples at microscopy to nematode larvae or to eggs of hookworms were cultured in agar plate. Larvae that developed in culture were described morphologically using passwords. We identified the most relevant differential morphologic features and illustrated them using microphotography. Results: The most relevant morphologic features that allow differentiating these nematodes were the longitude of the oral cavity and the prominence of the genital primordium for the rabditiform larva; the shape of the body, the terminal end of the tail and the diameter of the anterior extreme of the intestine in relation to the esophagus for the filariform larvae. Conclusions: Hookworms and S. stercoralis can be specifically identified by optic microscopic examination of their larval stages developed in culture. We recommend this methodology for conventional microbiology laboratories due to the requirement of simple equipment.

KEYWORDS: Strongyloides stercoralis, Ancylostomatoidea, Necator americanus. (Source: MeSH NLM).

Laboratorio de Parasitología, Metaxénicas y Zoonosis, Hospital Regional Lambayeque. Lambayeque, Perú.

a Doctor en ciencias, Biólogo-Microbiólogo. 


\section{INTRODUCCIÓN}

Según un informe de la Organización Mundial de la Salud (OMS), más de 1,5 millones de personas alrededor del mundo, principalmente de áreas tropicales y subtropicales, están infectados con parásitos geohelmintos. Asimismo, alrededor de 568 millones de niños en edad escolar viven en regiones de intensa transmisión de estas parasitosis, en los que incluyen la estrongiloidiasis y uncinariasis (1). La estrongiloidiasis (causada por Strongyloides stercoralis y S. fullebornii), y uncinariasis (causadas por Ancylostoma duodenale, Necator americanus y eventualmente por $A$. ceylanicum), son infecciones parasitarias helmínticas endémicas en varias regiones del Perú e hiperendémicas en otras, con frecuencias superiores a $6 \%$ y $30 \%$ respectivamente $(2,3)$.

Sin embargo, se desconoce varios aspectos de la epidemiología y clínica de estas enfermedades en el Perú, entre otras razones, debido a que los estudios de investigación y de diagnóstico de laboratorios clínicos en el país, no consideran técnicas específicas para la detección y diferenciación de las especies parasitarias en mención.

Conocer la diferencia entre las larvas es importante para la salud pública porque permite identificar la especie de nematodo y por lo tanto la enfermedad, en un contexto nacional donde la frecuencia y distribución de estas dos parasitosis aún se desconocen. Asimismo, diferenciar correctamente las larvas de uncinarias y $S$. stercoralis en el laboratorio clínico es relevante en el manejo clínico del paciente, por cuanto las enfermedades requieren tratamiento antiparasitario diferenciado, y sus complicaciones y riesgos no son las mismas. Por otra parte, en estrongiloidiasis, la presencia de larvas filariformes en heces, además de las rabditiformes, demuestra la multiplicación acelerada del parásito en su ciclo autoinfectivo, indicando un síndrome de hiperinfección.

Por esta razón, este estudio tuvo como objetivo describir las características morfológicas diferenciales más importantes de los estadíos larvarios rabditiforme y filariforme de las uncinarias (A. duodenale y $N$. americanus), y $S$. stercoralis, para su identificación específica en laboratorio clínico convencional.

\section{MATERIAL Y MÉTODOS}

Estudio descriptivo, observacional. Desde julio de 2015 a agosto de 2016 las muestras fecales positivas a larvas de nematodos (Strongyloides) o huevos de uncinaria, detectados por examen microscópico directo en el Laboratorio de Parasitología, Metaxénicas y Zoonosis del Hospital Regional Lambayeque, fueron analizadas por la técnica de cultivo en placa de agar (4).

\section{Cultivo y desarrollo de los estadios larvarios}

El cultivo en placa de agar permitió desarrollar todos los estadios larvarios para su posterior descripción e ilustración de las características morfológicas diferenciales más importantes mediante microscopía óptica. En general se siguieron los procedimientos descritos previamente por Botero y Restrepo, 2012 (4), a los que se le hicieron algunas modificaciones.

Las muestras de materia fecal incluidas en el estudio fueron conservadas a temperatura ambiente $\left(20\right.$ a $25{ }^{\circ} \mathrm{C}$ ), hasta ser cultivadas en un lapso de tiempo no mayor a ocho horas desde su recolección. La conservación en refrigeración de 2 a $8{ }^{\circ} \mathrm{C}$ no se recomendó por considerarse adversa para mantener la viabilidad y motilidad de las larvas de $S$. stercoralis y la viabilidad de los huevos de uncinaria. La técnica de cultivo en placa de agar consistió en colocar $2 \mathrm{~g}$ de materia fecal en el centro de la placa usando la técnica aséptica microbiológica, se selló la placa con parafilm y se incubó a placa derecha a $30^{\circ} \mathrm{C}$ y en condiciones de aerobiosis. La positividad del cultivo y el desarrollo de las larvas se evidenció indirectamente por el crecimiento de colonias bacterianas dispuestas en "caminos serpenteantes" sobre la superficie del agar. Las larvas se recuperaron de la superficie del agar agregando $10 \mathrm{ml}$ de formalina al $10 \%$, luego la suspensión larvaria se dejó sedimentar espontáneamente y conservó en un tubo de centrífuga.

Las modificaciones a la técnica referenciada consistieron en los siguientes puntos:

1. El medio de cultivo usado fue el Mc Conkey en lugar del Agar Nutritivo. El primer medio ofreció colonias bacterianas visualmente más notorias (colonias lactosa positivas de color grosella con precipitado de sales biliares), además, fue un sustrato favorable para el desarrollo de las larvas (similar al ofrecido por el Agar Nutritivo), comprobándose que los componentes químicos selectivos del medio no afectaron su desarrollo.

2. Las muestras fecales de consistencia semisólida y sólida fueron ablandadas agregando solución salina estéril y homogenizadas hasta convertirla en una suspensión acuosa densa. Se inoculó $2 \mathrm{ml}$ 
de la suspensión usando pipetas plásticas estériles evitando salpicaduras y aerosoles. Esta modificación permitió garantizar la movilidad de las larvas en la muestra inoculada, a partir del cual se desplazan hacia la superficie del agar diseminando bacterias en su trayecto, convirtiendo su cuerpo en una viva asa de siembra.

3. La incubación para desarrollar larvas de Uncinaria se realizó hasta por seis días, en lugar de dos (la incubación para $S$. stercoralis sí fue de dos días). Los huevos de uncinaria requirieron mayor tiempo de incubación para eclosionar (48 a 72 horas) y por lo tanto el desarrollo a larvas filariformes también se prolongó.

Descripción de las características morfológicas diferenciales relevantes

Las larvas recuperadas en distintos momentos de la incubación se estudiaron mediante microscopía óptica. Las características morfológicas diferenciales de los estadíos rabditiforme y filariforme de las tres especies fueron verificadas usando claves taxonómicas descritas previamente (5-7). Además, se priorizaron en número de orden aquellas características más relevantes, teniendo como criterio su conservación específica, facilidad de visualización y aplicabilidad en laboratorios de análisis clínicos convencionales. Asimismo, se registraron las características morfológicas mediante microfotografías usando un microscopio con software para establecer dimensiones (Leica®).

El protocolo de estudio fue evaluado y aprobado por el comité de ética en investigación del Hospital Regional Lambayeque.

\section{RESULTADOS}

Se obtuvieron cultivos positivos y desarrollo exitoso de larvas filariformes de $S$. stercoralis entre dos a tres días de incubación. Mientras que se requirió de tres a cuatro días para obtener larvas rabditiformes de Uncinaria y cinco a seis días para las filariformes. El tiempo menor requerido para el desarrollo de las larvas de S. stercoralis fue debido a que en el momento de la siembra, la materia fecal ya contiene larvas rabditiformes (eclosionadas en el intestino), e incluso larvas filariformes en casos de síndromes de hiperinfección (Figura 1A).

Las características morfológicas más relevantes para diferenciar las larvas de este primer estadio (rabditiformes), se muestran en la tabla 1 y se ilustran en las figuras 1B y 2A. Cabe destacar que en este estadío las uncinarias $A$. duodenale y $N$. americanus no son diferenciables morfológicamente mediante microscopía óptica.

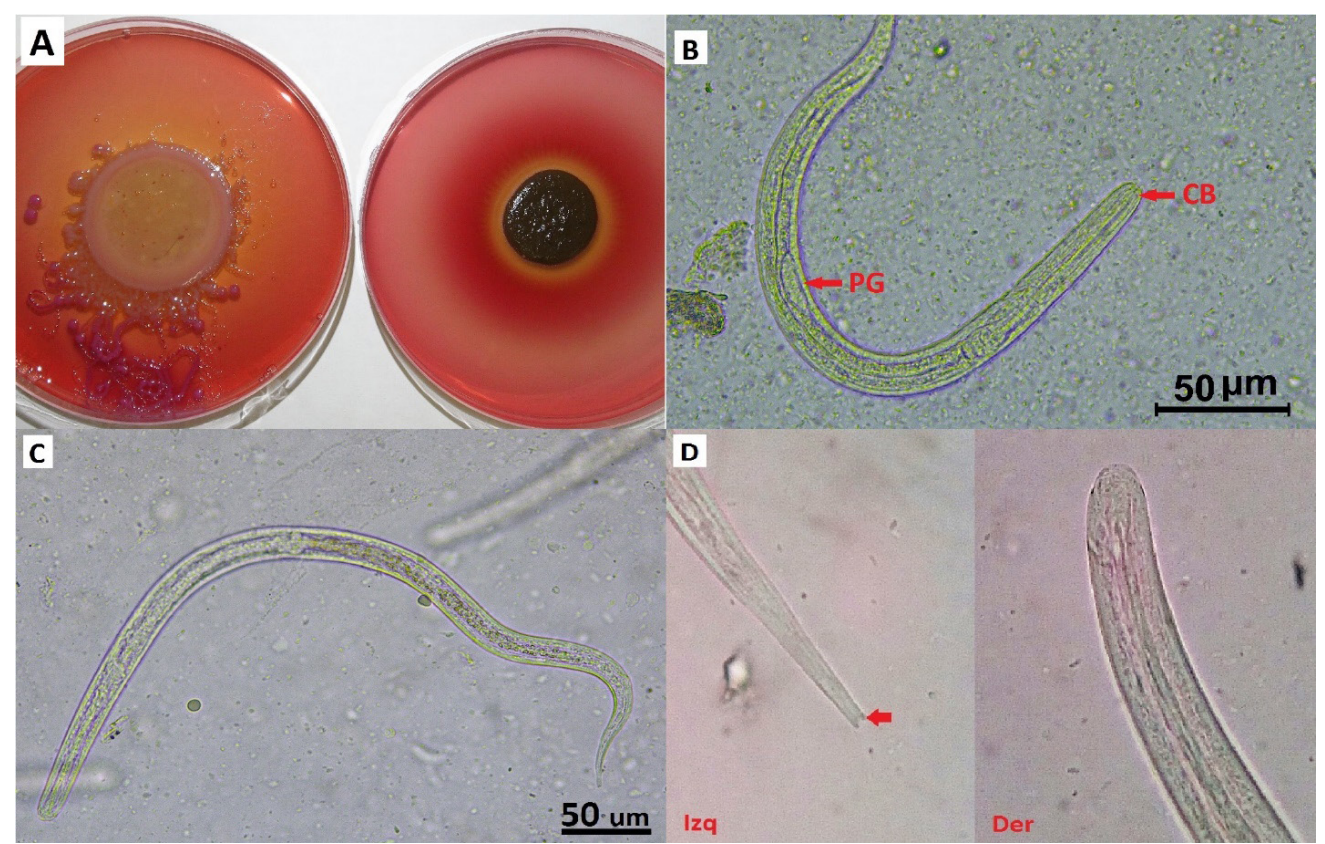

Figura 1. A: Cultivo de agar en placa para uncinarias y S. stercoralis, positivo (izquierda) y negativo (derecha). Larvas de $S$. stercoralis: B: estadio rabditiforme, C: estadio filariforme y CB: Cavidad bucal, PG: Poro genital. D: extremo posterior (izquierda) y anterior (derecha). 
Tabla 1. Características morfológicas diferenciales (descritas en orden de relevancia), de las larvas en estadío rabditiforme de $S$. stercoralis y Uncinaria.

\begin{tabular}{|c|c|c|}
\hline Características & S. stercoralis & Uncinaria \\
\hline Cavidad bucal & Corta & $\begin{array}{l}\text { Larga, con apariencia de surco } \\
\text { en una distancia igual o mayor al } \\
\text { ancho del cuerpo anterior. }\end{array}$ \\
\hline Poro genital & Prominente, corto y ahusado & Discreto \\
\hline Extremo terminal de la cola & Afilada & Marcadamente afilada y estrecha \\
\hline Diámetro de la cabeza en relación al cuerpo anterior & Similar & Menor \\
\hline Rango de longitud $(\mu \mathrm{m})$ & $300-380 \mu \mathrm{m}$ & $250-300 \mu \mathrm{m}$ \\
\hline
\end{tabular}

Tabla 2. Características morfológicas diferenciales (descritas en orden de relevancia), de las larvas en estadío filariforme de S. stercoralis y Uncinaria.

\begin{tabular}{llll}
\hline \multicolumn{1}{c}{ Características } & \multicolumn{1}{c}{ S. stercoralis } & \multicolumn{1}{c}{ Uncinaria } \\
\hline Forma del cuerpo & Delgado & Corto y de apariencia robusta \\
Extremo terminal de la cola & Bifurcada & Estrechamente alargada o afilada \\
Diámetro del esófago en relación al intestino & Similar & Grande & \\
Rango de longitud $(\mu \mathrm{m})$ & $490-630$ & $660-720$ & N. americanus \\
& & A. duodenale & Similar \\
Diámetro del extremo anterior del intestino en relación al esófago & Menor & Estrechamente alargada & Afilada \\
Extremo terminal de la cola & & Poco perceptible & Marcado \\
Estriamiento de la envoltura & & Por detrás & Por delante \\
Ubicación del poro genital en relación a la porción media del intestino & Plana & Redondeada \\
Forma de la cabeza & & $660-720$ & $590-660$ \\
Rango de longitud $(\mu \mathrm{m})$ & & & \\
\hline
\end{tabular}

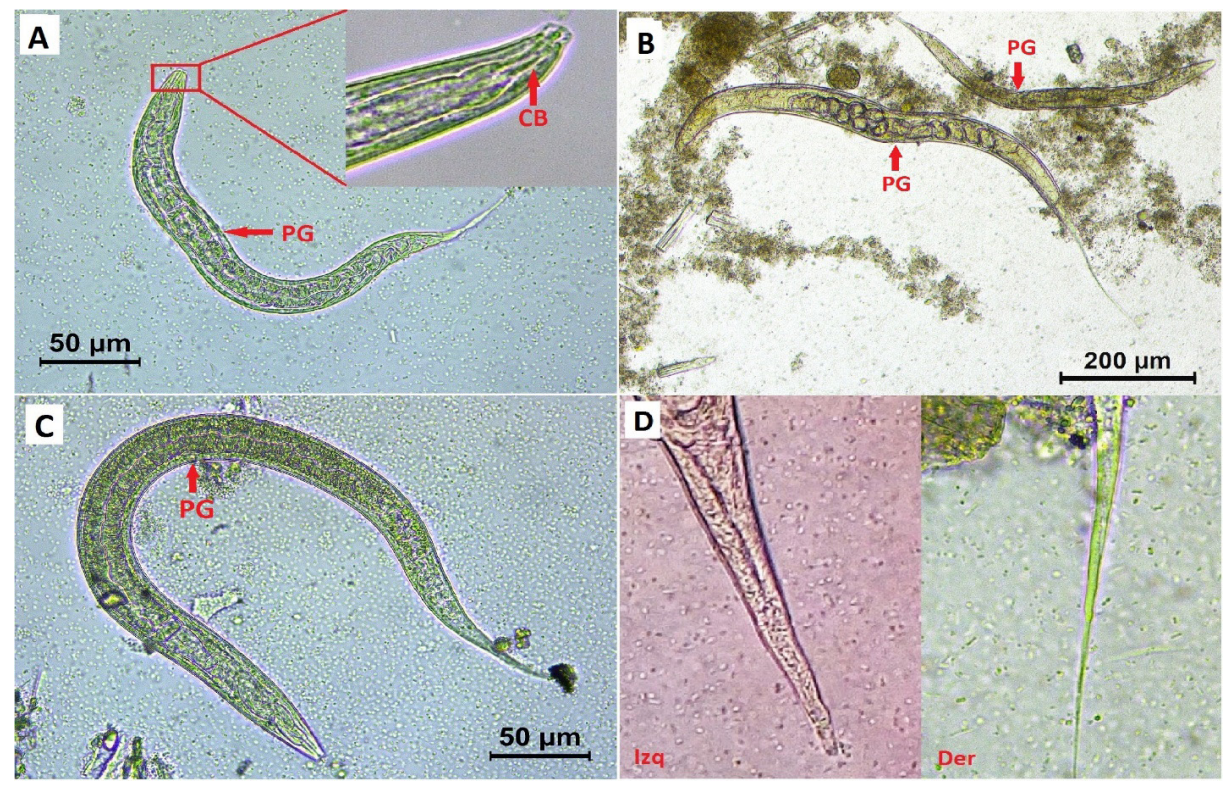

Figura 2. Larvas de Uncinaria: A) estadío rabditiforme, B) estadío filariforme de $A$. duodenale, C) estadío filariforme de $N$. americanus y D) extremo terminal del estadío filiforme de $N$. americanus (izquierda) y A. duodenale (derecha). CB: Cavidad bucal, PG: Poro genital. 


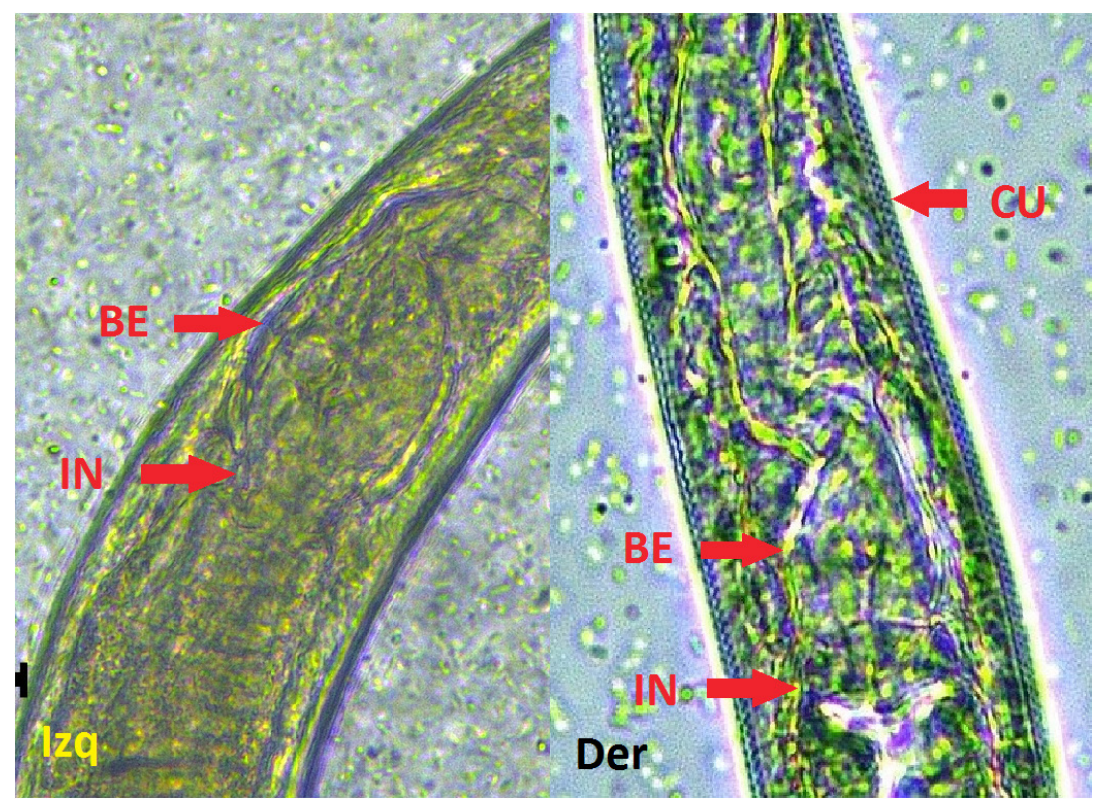

Figura 3. Extremo proximal de larvas filariformes de $A$. duodenale (izquierda) y $N$. americanus (derecha), mostrando diferencias en el estriamiento de la cutícula y el diámetro del extremo anterior del intestino en relación al esófago.

BE: bulbo esofágico, IN: Intestino, CU: cutícula.

Las características morfológicas más relevantes para diferenciar las larvas filariformes de los nematodos en estudio se muestran descritas en la tabla 2 e ilustradas en las figuras $1 \mathrm{C}, 1 \mathrm{D}, 2 \mathrm{~B}, 2 \mathrm{C}$ y 2D. En la figura 3, se muestran diferencias entre larvas filariformes de $A$. duodenale y $N$. americanus.

\section{DISCUSIÓN}

Si bien existen técnicas moleculares y serológicas para detectar y diferenciar la especie helmíntica en cuestión, éstas son caras y requieren laboratorios complejos y equipamiento costoso y sofisticado, que no están al alcance de la mayoría de los laboratorios clínicos públicos (8-10). Mientras que, el cultivo in vitro de las larvas y su posterior diferenciación morfológica mediante microscopía óptica es barato y puede implementarse en laboratorios con equipamiento básico de cultivos microbiológicos. No obstante, esta técnica requiere de un analista calificado y entre 2 a 6 días de tiempo para culminar el examen.

La técnica de cultivo en placa provee dos utilidades:

1. Permite la detección de $S$. stercoralis y Uncinaria al segundo y cuarto día respectivamente (evidenciado por el crecimiento bacteriano), con una alta sensibilidad ( $89 \%$ o más), en comparación a otras técnicas convencionales de microscopía o cultivo $(11,12)$. Es en este momento del cultivo que se podría realizar el estudio morfológico de las larvas rabditiformes y diferenciar $S$. stercoralis y Uncinaria.

2. Da lugar al desarrollo completo de las larvas, desde la incubación del huevo (caso de Uncinaria), hasta el estadío filariforme. Sólo en este último estadío se pueden diferenciar morfológicamente las especies de uncinarias, razón por el que es tan importante que la técnica de cultivo promueva la evolución completa.

Las larvas rabditiformes (larvas recién eclosionadas, también denominadas L1, de $S$. stercoralis y Uncinaria presentan una longitud de 250 a $380 \mu \mathrm{m}$ y se caracterizan por presentar un cuerpo corto, similar al nematodo del género Rhabditis. Mientras que, el estadío filariforme, también denominado infectante, es de mayor tamaño $(490-720 \mu \mathrm{m})$, evolucionan mediante sucesivas mudas en condiciones de humedad y temperaturas adecuadas, y se caracterizan presentar a un cuerpo alargado, similar al nematodo del género Filaria.

El tamaño relativo de las larvas es una aproximación específica importante, sin embargo no lo considero un criterio relevante a recomendar debido a que no todos los laboratorios cuentan con láminas patrón o microscopios con sistemas informáticos para realizar las mediciones. 
No fue posible realizar estudios inmunológicos o moleculares a las larvas para complementar los resultados, lo cual consideramos una limitación del estudio.

Se concluye que la longitud de la cavidad bucal y la prominencia del poro genital son las características morfológicas más relevantes para diferenciar las larvas rabditiformes de uncinarias y $S$. stercoralis; asimismo, en el estadío filariforme lo son la forma del cuerpo, el extremo terminal de la cola y el diámetro del extremo anterior del intestino en relación al esófago.

\section{Fuentes de financiamiento y de conflictos de interés:}

Una parte del estudio fue autofinanciado y otra por la Dirección de Investigación del Hospital Regional Lambayeque que financió los gastos de uso de infraestructura y equipamiento. El autor declara no tener conflictos de interés.

\section{Correspondencia:}

Heber Silva-Díaz

Dirección de Investigación del Hospital Regional Lambayeque.

Av. Vía de Evitamiento Norte con Av. El Progreso. Chiclayo, Perú.

Teléfono $\mathrm{N}^{\circ} 051965902275$

Correo electrónico: hsilva@hrlamb.gob.pe

\section{REFERENCIAS BIBLIOGRÁFICAS}

1. World Health Organization. Soil-transmitted helminth infections. Washington: World Health Organization; 2017. (Citado el 16 de diciembre del 2017) Disponible en: http://www.who.int/mediacentre/factsheets/ fs $366 / \mathrm{en} /$

2. Marcos R, Cabrera R, Machicado JD, et al. Distribution of prevalence of Strongyloides stercoralis in Peru (1981-2010): an exploratory study. Rev Peru Parasitol. 2010; 18(2):39-49.
3. Ibáñez N, Jara C, Guerra M, Díaz L. Prevalencia del enteroparasitismo en escolares de comunidades nativas del Alto Marañón, Amazonas, Perú. Rev Peru Med Exp Salud Publica. 2004; 21(3):126-33.

4. Botero D, Restrepo M. Parasitosis humanas incluye animales venenosos y ponzoñosos. Medellin: Corporación para Investigaciones Biológicas; 2012.

5. Viney M, Lok J. The biology of Strongyloides spp. WormBook. 2015.p.1-17. (Citado el 16 de diciembre del 2017) Disponible en: http://www. w o r m b o o k. org / c h a p te r s / w w w genomesStrongyloides.2/strongyloides.2.html

6. Yoshida Y. Morphological differences between Ancylostoma duodenale and Necator americanus in the fourth larval stage. J Parasitol. 1966; 52(1):122.

7. Beltrán $M$, Tello $R$, Náquira $C$. Manual de procedimientos de laboratorio para el diagnóstico de los parásitos intestinales del hombre. Lima: Instituto Nacional del Perú; 2003.

8. Chidambaram M, Parija SC, Toi PC, et al. Evaluation of the utility of conventional polymerase chain reaction for detection and species differentiation in human hookworm infections. Trop Parasitol. 2017; $7(2): 111-6$.

9. Gyawali P, Sidhu JPS, Ahmed W, Jagals P, Toze S. Comparison of culture-based, vital stain and PMAqPCR methods for the quantitative detection of viable hookworm ova. Water Sci Technol. 2017; 75(11):2615-21.

10. Khurana S, Sethi S. Laboratory diagnosis of soil transmitted helminthiasis. Trop Parasitol. 2017; 7(2):86-91.

11. Barreto RE, Narváez J, Sepúlveda NA, et al. Combination of five diagnostic tests to estimate the prevalence of hookworm infection among schoolaged children from a rural area of colombia. Acta Trop. 2017; 173:160-70.

12. Campo L, Gutiérrez LA, Cardona J. Infección por Strongyloides stercoralis: metanálisis sobre evaluación de métodos diagnósticos convencionales (1980-2013). Rev Esp Salud Publica. 2014; 88(5):581-600.

Recibido: 10/02/2018

Aceptado: 27/09/2018 